\title{
Measure learning effectiveness among children using EEG device and mobile application
}

\author{
Magrizef Gasah $^{1}$, Aslina Baharum², Nurul Hidayah Mat Zain ${ }^{3}$ \\ ${ }^{1,2}$ Faculty of Computing and Informatics, Universiti Malaysia Sabah, 88400 Kota Kinabalu, Sabah, Malaysia \\ ${ }^{3}$ Faculty of Computer and Mathematical Sciences, Universiti Teknologi MARA (UiTM) Melaka, Kampus Jasin, 77300
}

Merlimau, Melaka, Malaysia

\begin{tabular}{l} 
Article Info \\
\hline Article history: \\
Received Apr 20, 2019 \\
Revised Jun 24, 2019 \\
Accepted Jul 10, 2019 \\
\hline Keywords: \\
Application \\
Children \\
EEG \\
Learning effectiveness \\
Mobile learning
\end{tabular}

\begin{abstract}
This paper presents a method in measuring the learning effectiveness among children using EEG device and Mobile Application. In this study, an approach to measure the children learning effectiveness using a mobile learning application and EEG device have been developed. The method used to develop the approach was from the extensive literature review from previous research related to children learning effectiveness and its experimental works. A quantitative method was used to measure the effectiveness of children learning and the result of this experimental work shows that children learning effectiveness can reach nearly $73 \%$. Since lot of teachers and student having trouble in accessing the learning activity whether it was effective or not, this study shown a significant way to solve such problem.

Copyright $@ 2020$ Institute of Advanced Engineering and Science. All rights reserved.
\end{abstract}

\section{Corresponding Author:}

Aslina Baharum,

Faculty of Computing and Informatics,

Universiti Malaysia Sabah,

88400 Kota Kinabalu, Sabah, Malaysia.

Email: aslina@ums.edu.my

\section{INTRODUCTION}

Numerous reviews on the effectiveness of e-Learning were within the context of language learning that primarily includes in criteria of quantitative studies [1], transparency of statistical information [2-3] or similarity of the predefined outcome measures [4]. Moreover, only few researches which included both qualitative and quantitative studies can be considered as relevant [5]. This because, a set of classifications was frequently used to identify the effectiveness of e-Learning solution such as, several papers use both 'learning outcome' and 'satisfaction' as definitions for effectiveness [6-8]. The number of papers in this list would of course change if the remaining abstracts were coded, but the author's find that the most common definitions are expected to stay relatively stable, as they have not significantly changed in recently reviewed abstracts. Having multiple ways of understanding the effectiveness of e-Learning allows professionals and researchers substantial flexibility in defining, measuring and determining the effectiveness of an e-Learning solution [9]. The results can help teachers attributed improved in student learning to various technology use; online communication with peers and experts reduced teacher isolation, enhanced professional practice and gave access to perspectives and experiences otherwise unavailable; but the additional workload discouraged several teachers' [10].

Quantitative method was a research method that deals with numbers and anything that was measurable such as investigation of occurrences and their relationships [11]. This includes the numerical data analysis such as the frequency, mean and standard deviation. Furthermore, the theory was deductively and mentioned at the beginning of the research expectation outcomes. The quantitative method objective was to test or to verify a theory by collecting the data theory and reflects on its confirmation or disconfirmation by 
the results [12]. Finally, the quantitative method was a data collection executed to verify the research's facts and phenomena. This can be achieved by measuring or comparing the variable of the data and must be reported in statistical analysis where it is a suitable method in this study to measure the learning effectiveness among children.

Mobile technologies have become an integral part of people's daily life that showed a significant progress in its development within recent years [13]. Nowadays, the m-learning (Mobile Learning) has become the attention and focus a few scientists and work on its development and distribution from all over the world [14-16]. The mobile learning term denotes the use of mobile applications installed on a mobile device (tablet or smartphone) that used in the education process at school [17-18]. The implementation of this mobile learning is not a simple process when it is for young age students and children's learning. Textbook's author, children (students), parents and teachers play an important role in the formation of the children character, interests and social behaviour through learnings' process [19]. Therefore, by applying the Mlearning in children education, it's shown a significant contribution for children to build their character, behaviour and interest in learning. This could be done by developing an e-learning application that could run on an Android device platform.

The Electroencephalograms (EEG) record the electric activity of a human's brain through electrodes that are attached to the scalp that used traditionally for medical purposes in diagnosis and management of various brain-related disorders such as the case of epilepsy and abnormal neuronal activity [20]. The EEG feature also assists in tracking patients' brain activities while patients are carrying out their daily tasks. EEG's also capable of monitoring the changes in someone's emotions shown by the brain signals. Moreover, (Potter \& Bolls, 2012) explain that the EEG was a direct measure of central nervous system activity that was initiated by information processing in the brain [21]. Besides, (Skroumpelou et al., 2015), pointed out that EEG was a brain imaging tool that supplies researchers with an insight into human's affective state of mind [22]. According to (Ramirez, 2012) the EEG device could identify the positive emotion from signal of the brain wave with high accuracy [23]. According to [24], the positive emotion felt by the student is directly proportional to the level of learning effectiveness. Now, there are few EEG device already available in market to detect the human emotion and learning effectiveness.

\section{RESEARCH METHOD}

An already developed mobile learning application ('Sains Awal PraSekolah') was used in this research and an appropriate questionnaire was created. The mobile learning application was evaluated using two android phones (one where the mobile learning application installed and one to monitor the EEG device result) in order to achieve that all aspects need to be considered like the effectiveness of the mobile learning. The EEG device that was used in this research was MindWave EEG headset and Effective learner application. The Effective learner application used to monitor EEG learning effectiveness result in real time. After the data have been collected, the data then analyzed. Figure 1 shows the research method that uses data collection of quantitative as its technique. The research method of this research was as follow:

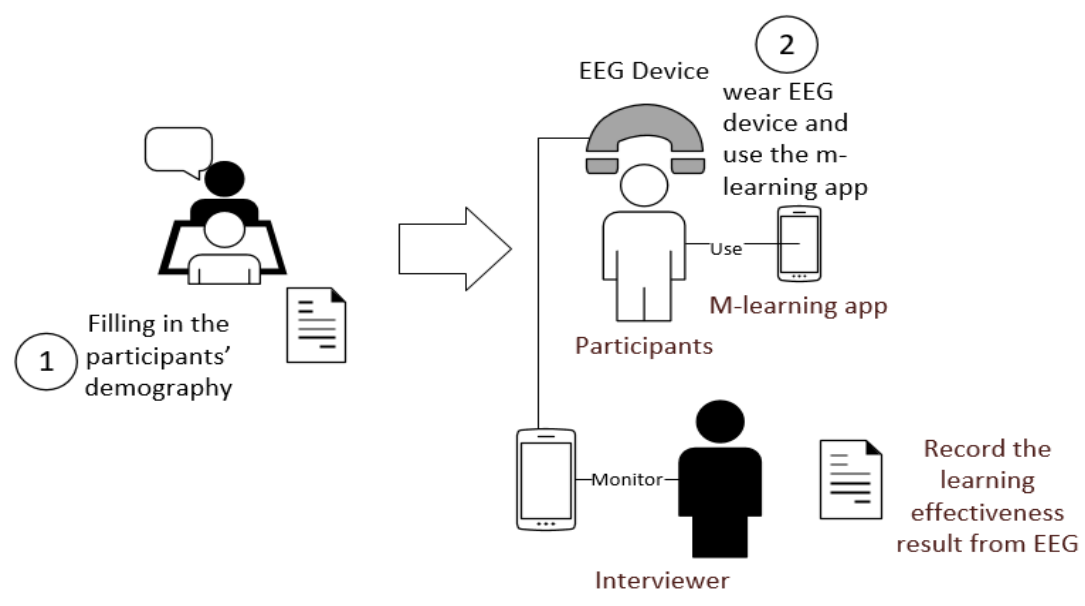

(3)

Figure 1. The research method in the research 
Firstly, the demography of the participants was recorded so that the user information is recorded. Next, The participants will wear an EEG device that monitors the participant effectiveness percentage while using an m-learning application while monitored by the interviewer. Finally, the rate result from the EEG device was recorded according to the level of effectiveness stated in the result

\section{RESULTS AND ANALYSIS}

The evaluation of the learning effectiveness of the mobile learning application was conducted in three different locations based on its sociology and economy. This to confirm whether that the mobile learning application effective in different level of technology exposure or not. The evaluation was conducted at a different location in Sabah (a state in Malaysia) that includes rural school (Tadika Advent Goshen Kota Marudu), suburban school (Pacos Trust Penampang) and urban school (Pusat Minda Lestari UMS Kota Kinabalu). There is a total of 104 participants that involve in the evaluation that consists of 98 children and 6 teachers. The demography of the participants is as follows.

In total, 98 children participated in this study. As shown in Table 1, the children distributed in the age groups of 4 years and 5 years old. This profile was typical of kindergarten children in the Malaysian population. In addition, the demographics of the data showed that about 47 (47.959\%) of the children from the rural area, $22(22.449 \%)$ from the suburban area and $29(29.592 \%)$ from the urban area. The category of the area was identified by the Majlis Perbandaran Sabah. Regarding the race classification, the number of Kadazan, Dusun, Melayu, Timor and Foreign (Japanese) were 21\%, 48\%, 27\%, $1 \%$ and $1 \%$ respectively.

Table 1. The Demography of Data Collected for Children

\begin{tabular}{ccccccc}
\hline Question & Range & \multicolumn{3}{c}{ Frequency } & \multicolumn{3}{c}{ Percentage } \\
& & Rural & Suburban & Urban & Total & \\
\hline \multirow{2}{*}{ Gender } & Male & 25 & 12 & 15 & 52 & 52.1 \\
& Female & 22 & 10 & 14 & 46 & 46.9 \\
& Total & 47 & 22 & 29 & 98 & 100 \\
Age & 4 years old & 12 & 8 & 4 & 24 & 24.5 \\
& 5 years old & 35 & 14 & 25 & 74 & 75.5 \\
& Total & 47 & 22 & 29 & 98 & 100 \\
& Kadazan & 1 & 20 & 21 & 21.4 & 1 \\
& Dusun & 45 & 2 & 1 & 48 & 49.0 \\
& Melayu & - & - & 27 & 27 & 27.6 \\
& Timor & 1 & - & - & 1 & 1.0 \\
& Foreign (Japanese) & - & - & 1 & 1 & 1.0 \\
& Total & 47 & 22 & 29 & 98 & 100 \\
\hline
\end{tabular}

As of the teacher, a total of 6 teachers involved. Table 2 shows the demography of teacher that articipated during the evaluation. A total of 6 teachers are interviewed where 2 teachers for each school is interviewed respectively. $3(50 \%)$ of the teacher are between 20-30 years old and $3(50 \%)$ of the rest are between 30 to 40 years old. Next, $2(40 \%)$ of the teacher are Kadazan race and $4(60 \%)$ the rest are Dusun race.

Table 2. The Demography of Data Collected for Teacher

\begin{tabular}{|c|c|c|c|c|c|c|}
\hline \multirow[t]{2}{*}{ Question } & \multirow[t]{2}{*}{ Range } & \multicolumn{4}{|c|}{ Frequency } & \multirow[t]{2}{*}{ Percentage } \\
\hline & & Rural & Suburban & Urban & Total & \\
\hline \multirow[t]{2}{*}{ Gender } & Female & 2 & 2 & 2 & 6 & 100 \\
\hline & Total & 2 & 2 & 2 & 6 & 100 \\
\hline \multirow{3}{*}{ Age } & 20-30 years old & 2 & 1 & & 3 & 50 \\
\hline & $30-40$ years old & & 1 & 2 & 3 & 50 \\
\hline & Total & 2 & 2 & 2 & 6 & 100 \\
\hline \multirow[t]{3}{*}{ Race } & Kadazan & & 1 & 1 & 2 & 40 \\
\hline & Dusun & 2 & 1 & 1 & 4 & 60 \\
\hline & Total & 2 & 2 & 2 & 6 & 100 \\
\hline
\end{tabular}

\subsection{Result of Electroencephalograms (EEG) Device}

The Electroencephalogram (EEG) device capable of recording the brain activity in real time and shows the learning effectiveness using the MindWave EEG headset and its application. Therefore, the EEG device could be considered as a reliable device to detect the children learning effectiveness. According to (Gasah et al., 2018), children focus, and attention are only between three to five minutes [25]. Since the 
average of children attention only between three to five minutes, the data between that period only, will be considered for evaluation because children were in their full attention during that period. Table 3, Table 4 and Table 5 shows the result of the EEG. The percentage value represents the learning effectiveness experienced by the children less than fifty per cent $(<50 \%)$ means less effective and more than fifty per cent (>50\%) means effective learning.

Table 3 shows the EEG device score for rural children. The score of the EEG device for less than 3 minutes indicate that almost $51.537 \%$ of effectiveness in children from 7 children only. The mean increases to $53.208 \%$ when the period are less than 5 minutes were taken from 25 children. This result the opposite from the expected result from [13] because the effectiveness of learning should be decreased when the time increases.

Table 3. EEG Device Score at "Tadika Advent Goshen"

\begin{tabular}{|c|c|c|c|c|c|c|}
\hline \multicolumn{7}{|c|}{ Rural Kids (Kota Marudu) } \\
\hline Minute & & No & Minimum & Maximum & Mean & Std. Deviation \\
\hline \multirow[t]{3}{*}{$<3$ Mins } & Time (mm:ss) & 7 & $1: 38$ & $2: 55$ & $2: 22$ & 0.02 \\
\hline & Percentage $(\%)$ & 7 & $24: 2$ & 67.2 & 51.357 & 16.52 \\
\hline & Valid N (listwise) & 7 & & & & \\
\hline \multirow[t]{3}{*}{$<5$ Mins } & Time (mm:ss) & 25 & $1: 38$ & $4: 47$ & $3: 24$ & 0.03 \\
\hline & Percentage (\%) & 25 & 24.2 & 95 & 53.208 & 19.68 \\
\hline & Valid N (lustwise) & 25 & & & & \\
\hline
\end{tabular}

Table 4 shows the EEG device score for suburban children. The score of the EEG device for less than 3 minutes indicate that almost $82.186 \%$ of effectiveness in children from 7 children. This then shows a significantly decreasing to $74.41 \%$ when the period is less than 5 minutes were taken from 10 children. This result followed the prediction of the result in phase one where the effectiveness in learning will be decreasing to time. Even though, the level of high level of effectiveness that reaches more than $82 \%$ show that the mobile learning application in this area could build a positive emotion to children.

Table 4. EEG Device Score at "Pacos Trust"

\begin{tabular}{|c|c|c|c|c|c|c|}
\hline \multicolumn{7}{|c|}{ Rural Kids (Kota Marudu) } \\
\hline Minute & & No & Minimum & Maximum & Mean & Std. Deviation \\
\hline \multirow[t]{3}{*}{ <3 Mins } & Time (mm:ss) & 7 & $0: 36$ & $2: 51$ & $1: 53$ & 0.04 \\
\hline & Percentage $(\%)$ & 7 & 68.3 & 100 & 82.186 & 11.18 \\
\hline & Valid N (listwise) & 7 & & & & \\
\hline \multirow[t]{3}{*}{$<5$ Mins } & Time (mm:ss) & 10 & $0: 36$ & $4: 35$ & $2: 35$ & 0.06 \\
\hline & Percentage $(\%)$ & 10 & 39.8 & 100 & 74.41 & 18.13 \\
\hline & Valid N (lustwise) & 10 & & & & \\
\hline
\end{tabular}

Table 5 shows the EEG device score for suburban children. The score of the EEG device for less than 3 minutes indicate that almost $78.667 \%$ of effectiveness in children were taken from 3 children only. This then shows a significantly decreasing to $61.752 \%$ when the period is less than 5 minutes were taken from 21 children. This result followed the prediction of the result in phase one where the effectiveness in learning will be decreasing to time. Even though, the level of high level of effectiveness that reaches more than $78 \%$ show that the mobile learning application in this area was effective.

Table 5. EEG Device Score at "PML UMS"

\begin{tabular}{|c|c|c|c|c|c|c|}
\hline \multicolumn{7}{|c|}{ Rural Kids (Kota Marudu) } \\
\hline Minute & & No & Minimum & Maximum & Mean & Std. Deviation \\
\hline \multirow[t]{3}{*}{$<3$ Mins } & Time (mm:ss) & 3 & 2:06 & $2: 59$ & $2: 27$ & 0.02 \\
\hline & Percentage (\%) & 3 & 71.4 & 92 & 78.667 & 11.56 \\
\hline & Valid N (listwise) & 3 & & & & \\
\hline \multirow[t]{3}{*}{$<5$ Mins } & Time (mm:ss) & 21 & 2:06 & $4: 56$ & $3: 59$ & 0.03 \\
\hline & Percentage $(\%)$ & 21 & $29: 9$ & 94 & 61.752 & 20.52 \\
\hline & Valid N (lustwise) & 21 & & & & \\
\hline
\end{tabular}




\subsection{Finding and Discussion}

The EEG device score shows that the average percentage of children having effective learning in less than three-minute study for rural children (51.357\%), suburban children $(82.186 \%)$ and urban children (78.667\%). This show that the m-learning application is effective in educating the suburban children compared to urban children and rural children.

Next, the study duration that more than three minute and less than five minutes show an increment for rural children (53.208\%) and decrement to suburban children (74.41\%) and urban children (61.752\%) respectively. This proves that the children learning efficiency will decrease within time because of two out of three schools shown the effectiveness decrement within this experiment. Finally, the average of the 3 areas could EEG score for less than three minutes is $70.737 \%$ with standard deviation of 13.087 and less than five minute is $63.123 \%$ with standard deviation of 19.444 . The result of the EEG scores also shown that the mobile learning application capable of teaching the children effectively nearly $63 \%-71 \%$.

\section{CONCLUSION}

The measuring of the effectiveness in learning not only give us a way to measure the effectiveness of the lesson taught but also give us a way to know the capability of the children level of understanding in classroom. Besides, the method used to measure the children learning effectiveness prove that the mobile learning application (Sains Awal Prasekolah) could teaches the children effectively. The result from this experimental work shown that the mobile learning application could effectively teaching the children nearly $63 \%-71 \%$. Moreover, the purpose of measuring the level of effectiveness in the mobile learning application is to help the developer and teacher to identify whether the mobile learning application developed really could help children in learning or not. Besides, this experimental work could also be applied to any teaching materials such as in classroom, e-learning and self-learning to identify the students learning effectiveness. This help the educational field in identifying the problem in learning and provide a solution or improvement regarding the effectiveness and learning amongst student or children.

\section{ACKNOWLEDGEMENT}

Researchers are thankful to Universiti Malaysia Sabah (UMS) for the support of the resources and necessary facilities for the preparation of the research. This study is currently funded by a UMSGreat Grant from Universiti Malaysia Sabah (GUG0299-2/2018).

\section{REFERENCES}

[1] Veneri, D. (2011) "The role and effectiveness of computer-assisted learning in physical therapy education: A systematic review", Physiotherapy Theory and Practice, vol. 27, no. 4, pp. 287-298.

[2] Grgurovic, M., Chapelle, C. A. and Shelley, M. C. (2013) "A meta-analysis of effectiveness studies on computer technologysupported language learning”, ReCALL, vol. 25, no. 2, pp. 165-198.

[3] Means, B., Toyama, Y., Murphy, R. F. and Baki, M. (2013) "The effectiveness of online and blended learning: A meta-analysis of the empirical literature", Teachers College Record, vol. 115, no. 3, p. 1.

[4] Rosenberg, H., Grad, H. A. and Matear, D. W. (2003) "The effectiveness of computer-aided, self-instructional programs in dental education: a systematic review of the literature", Journal of Dental Education, vol. 67, no. 5, pp. 524-532.

[5] Patterson, B. J., Krouse, A. M. and Roy, L. (2012) "Student outcomes of distance learning in nursing education: an integrative review”, Computers, Informatics, Nursing, vol. 30, no. 9, pp. 475-488.

[6] Harrington, S. S. and Walker, B. L. (2009) "The effects of computer-based fire safety training on the knowledge, attitudes, and practices of caregivers", Journal of Continuing Education in Nursing, vol. 40, no. 2, pp. 79-86.

[7] Jung, I., Choi, S., Lim, C. and Leem, J. (2002) "Effects of different types of interaction on learning achievement, satisfaction and participation in web-based instruction", Innovations in Education and Teaching International, vol. 39, no. 2, pp.153-162.

[8] Maloney, S., Haas, R., Keating, J. L., Molloy, E., Jolly, B., Sims, J., Haines, T. (2011) “Effectiveness of web-based versus face-to-face delivery of education in prescription of falls-prevention exercise to health professionals: Randomized trial", Journal of Medical Internet Research, vol. 13, no. 4.

[9] Noesgaard, S. S. (2014) "Supporting transfer of learning: Practice-based considerations on the applicability of transfer literature in online design", in the Conference Proceedings From Designs For Learning, Stockholm May 2014, pp. 1-5. Available: http://www.designsforlearning.nu/conference/program/pdf_webb/schack_noesgaard.pdf

[10] Bennett-Levy, J., Hawkins, R., Perry, H., Cromarty, P. and Mills, J. (2012) "Online cognitive behavioural therapy training for therapists: Outcomes, acceptability, and impact of support”, Australian Psychologist, vol. 47, no. 3, pp. 174-182.

[11] Rajagopal, I., \& Bojin, N. (2003). Quantitative Reserach Methods. First Monday, 8(1). https://doi.org/http://dx.doi.org/10.5210/fm.v8i1.1023 
[12] Creswell, J. W. (2017). Research Design. SAGE Publication Inc (4th ed., Vol. 91). United States of America: SAGE Publications Asia-Pacific Pte. Ltd.

[13] M. Sarwar and T. R. Soomro, "Impact of Smartphone's on Society," Eur. J. Sci. Res., vol. 98, no. 2, pp. 216-226, 2013.

[14] G. Botzer and M. Yerushalmy, "Mobile application for mobile learning," in Proceedings of IADIS International Conference on Cognition and Exploratory Learning in Digital Age (CELDA 2007), 2007, pp. 7-9.

[15] D. Dochev and I. Hristov, "Mobile learning applications ubiquitous characteristics and technological solutions," Bulg. Acad. Sci. Cybern. Inf. Technol., vol. 6, no. 3, 2006.

[16] R. Kraleva, V. Kralev, and D. Kostadinova, "A conceptual design of mobile learning applications for preschool children," arXiv Prepr. arXiv1606.05753, 2016.

[17] S. M. Hsu, S. F. Wang, Y. J. Hsieh, C. C. Cheng, and Y. J. Liao, "The physical and biomedical characteristics of the novel transmission type X-ray equipment,” Radiat. Meas., vol. 90, pp. 238-241, 2016.

[18] D. Parsons, H. Ryu, and M. Cranshaw, "A design requirements framework for mobile learning environments.," $J$. Comput. Phys., vol. 2, no. 4, pp. 1-8, 2007.

[19] J. S. Eccles, "Influences of parents education on their children's educational attainments: The role of parent and child perceptions," London Rev. Educ., vol. 3, no. 3, pp. 191-204, 2005.

[20] T. De Smedt and L. Menschaert, "VALENCE: affective visualisation using EEG," Digit. Creat., vol. 23 , no. 3-4, pp. 272-277, 2012.

[21] R. F. Potter and P. Bolls, "Psychophysiological measurement and meaning: Cognitive and emotional processing of media", 1st ed. New York: Routledge, 2012.

[22] K. Skroumpelou, P. Mavros, and A. H. Smith, "Are we there yet? Exploring distance perception in urban environments with mobile Electroencephalography," GIS Res. UK, 2015.

[23] R. Ramirez and Z. Vamvakousis, "Detecting emotion from EEG signals using the emotive epoc device," in International Conference on Brain Informatics, 2012, pp. 175-184.

[24] R. Pekrun, T. Goetz, W. Titz, and R. P. Perry, "Positive emotions in education," Oxford : Oxford University Press: Beyond coping: Meeting goals, visions, and challenges, 2002, pp. 149-173.

[25] M. Gasah and A. Baharum, "A Conceptual Framework for Emotional Connection towards E-learning Mobile Application Design for Children,” vol. 2018, 2018. 